\title{
PerCursos
}

\section{Geografia eleitoral no norte central do estado do Paraná: poder local e coronelismo}

\begin{abstract}
Resumo
No Brasil, os holofotes sobre a política nunca estiveram tão intensos. Igualmente intensos, estão a desconfiança da população, a comprovação dos casos de corrupção e o negligenciar da vida pública e do espaço público. Por isso, o objetivo principal deste artigo é refletir acerca da Geografia Eleitoral nos municípios do Norte Central do Estado do Paraná, demonstrando o poder local e o coronelismo, sobretudo nas pequenas cidades. Assim, o artigo pretende desmitificar que o coronelismo e a centralização política personificada em indivíduos ou famílias são características de áreas e regiões menos desenvolvidas. Para isso, o estudo, que ocorre na região Norte Central do Estado do Paraná, composta por 79 municípios, foi realizado por meio de levantamento bibliográfico e de dados secundários dos municípios da região, levantamento de dados eleitorais, entre 1947 e 2016, produção de material cartográfico e a realização da redação final deste artigo. Os resultados mostraram que a realidade apresentada atinge com maior intensidade algumas localidades, mas, como tendência, observa-se que as localidades da região Norte do Estado do Paraná, de forma geral, são atingidas igualmente pelo mesmo processo de poder local centralizado e pelo coronelismo.
\end{abstract}

Palavras-chave: Geografia política. Eleições - Paraná - História. Coronelismo no Norte do Paraná.

\section{Pedro Henrique Carnevalli Fernandes}

Doutor em Geografia pela

Universidade Estadual de

Maringá - UEM. Professor da

Universidade Estadual do Norte

do Paraná -UENP. Editor

Associado da Revista Geoingá.

Brasil

pedrofernandes@uenp.edu.br

\section{Guilherme Ferrari Oliveira}

Licenciado em Geografia pela

Universidade Estadual do Norte do Paraná - UENP. Professor da rede estadual e particular de ensino.

Brasil

guima.ferrari@hotmail.com

\section{Para citar este artigo:}

FERNANDES, Pedro Henrique Carnevalli; OLIVEIRA, Guilherme Ferrari. Geografia eleitoral no norte central do estado do Paraná: poder local e coronelismo. Revista PerCursos, Florianópolis, v. 21, n.46, p. 190 - 216, maio/ago. 2020.

DOI: $10.5965 / 1984724621462020190$

http://dx.doi.org/10.5965/1984724621462020190 


\title{
Election geography in the central north of the state of Paraná: local power and coronelismo
}

\begin{abstract}
In Brazil, the spotlight on politics has never been so intense. Equally intense is the mistrust of the population, evidence of corruption, and neglect of public life and public space. Therefore, this article's main objective is to reflect on Electoral Geography in the municipalities of the North Central of the State of Paraná, demonstrating local power and coronelismo, especially in small cities. Thus, the article aims to demystify that coronelismo and personified political centralization in individuals or families are characteristics of less developed areas and regions. For this, the study taking place in the North Central region of the State of Paraná, composed of 79 municipalities, was carried out through bibliographic and secondary data survey of municipalities in the region, a survey of electoral data, between 1947 and 2016, production of cartographic material and the final writing of this article. The results showed that the reality presented affects some localities with greater intensity, but, as a tendency, it is observed that localities in the Northern region of the State of Paraná, in general, are equally affected by the same process of centralized local power and coronelismo.
\end{abstract}

Keywords: Political Geography. Elections - Paraná Story. Coronelismo in North of Paraná. 


\section{Introdução}

No Brasil, os políticos e os administradores públicos têm perdido, cada vez mais, a confiança da população, seja pelos incontáveis casos de corrupção, seja pelo negligenciar, quase que constantemente, uma gestão pública voltada para os menos favorecidos. Logo, é comum encontrar exemplos de políticos envolvidos em casos de corrupção, dormindo em sessão pública e até assistindo filmes adultos em horário de expediente.

Por isso, o brasileiro, entre as 27 grandes economias do mundo, é quem menos confia em políticos, com apenas 6\% (CHADE, 2016). Em 2017, 65\% dos brasileiros não confiavam no presidente da República, Michel Temer (PMDB, atual MDB), e no Congresso Nacional (BILENKY, 2017). Em dezembro de 2019, segundo o Ibope (2019), 56\% dos brasileiros não confiavam no presidente da República Jair Bolsonaro (sem partido). Também no final de 2019, o Datafolha fez uma pesquisa avaliando a confiança de 12 figuras do cenário político brasileiro e apenas uma delas, um ex-juiz, Sérgio Moro, então Ministro de Estado da Justiça e Segurança Pública, teve nível de desconfiança inferior a 50\%, enquanto Jair Bolsonaro, Hamilton Mourão (PRTB), Vice-Presidente da República, Rodrigo Maia (Democratas), Presidente da Câmara dos Deputados, e Davi Alcolumbre (Democratas), Presidente do Senado, tiveram rejeição acima de 60\% (FARIA, 2020).

Essa desconfiança pode ter explicação no modelo do poder político brasileiro e no coronelismo, ou seja, é possível constatar que inúmeros parlamentares debatem e aprovam uma série de projetos de interesses pessoais ou de seus clãs familiares, sem pensar, planejar e legislar com base em uma política social de interesse coletivo. Logo, projetos de interesses particulares e/ou familiares são duvidosos quanto à relevância social, uma vez que destoam de projetos que visam proporcionar ao coletivo a emancipação humana.

Para exemplificar, a Revista Super Interessante (OS PIORES..., 2016) apresentou alguns projetos em que sua linha editorial questiona a relevância para o coletivo social: o projeto de Luiz Carlos Hauly (deputado federal pelo PSDB-PR) quer transformar o ensino superior em uma competição, sendo que apenas os primeiros passarão e os demais, mesmo com notas na média, serão reprovados; o projeto de Aureo (deputado federal 
pelo Solidariedade-RJ) propõe que futuros motoristas não precisem frequentar aulas de legislação na formação de condutores; o projeto de Carlos Marun (deputado federal pelo PMDB-MS) quer ver publicado o nome dos vencedores de loterias com prêmios superiores a dois mil salários mínimos; e o projeto de Takayama (deputado federal pelo PSC-PR) quer criar o cargo de deputado federal ultramarino para eleger parlamentar que represente grupos fora do Brasil em países com mais de cem mil brasileiros residentes.

Entende-se que esses exemplos de projetos, citados pelo editorial da Revista Super Interessante (OS PIORES..., 2016), caminham no sentido oposto ao engajamento político voltado à coletividade e à comunidade, defendido por Bauman (2007) e que embasam os ideais deste artigo. No primeiro caso citado, qual a relevância de criar uma competição na educação? No segundo projeto, qual o interesse coletivo para que motoristas não passem por formação adequada? Em que a divulgação do nome de vencedores de loteria vai melhorar o bem-estar social e emancipar a população? Finalmente, um projeto para eleger parlamentares para representar brasileiros no exterior não exigiria projetos voltados à eleição de parlamentares que representassem brasileiros em situação de pobreza, ou brasileiros negros, ou tantos outros segmentos sociais? Além disso, deputados federais trabalhando no exterior não diminuiriam o papel das embaixadas e do Itamaraty? Enfim, são indagações que pretendem motivar o debate que, certamente, é múltiplo, mas necessário.

Em resumo, a participação de todos, principalmente das classes desfavorecidas, é improvável caso o Estado se recuse - e é justamente o que ele faz - a ser um Estado social e político. Então, o papel e o alcance do poder local e a defesa do espaço e da vida pública, sobretudo para uma sociabilidade positiva, precisam se reorganizar de modo a eliminar a política sustentada pelo coronelismo, que se reproduz e se perpetua a partir de interesses particulares e/ou de seus familiares, e consolidar representatividades variadas do cotidiano e do contexto local. Por isso, o objetivo principal deste artigo é refletir acerca da Geografia Eleitoral nos municípios do Norte Central do Estado do Paraná, demonstrando o poder local e o coronelismo, sobretudo em municípios polarizados por pequenas cidades. Essa perspectiva de análise transita pelas eleições municipais, entre 1947 e 2016, a partir das eleições para o Poder Executivo. Com esse objetivo central, este 
artigo pretende desmistificar o senso comum de que o coronelismo e a centralização política personificada em indivíduos ou famílias são características de áreas e regiões menos desenvolvidas, como se não mais ocorressem no Sul do Brasil.

Os objetivos específicos são: discorrer acerca da base teórica da Geografia Política e Geografia Eleitoral; demonstrar a realidade atual da região Norte Central do Estado do Paraná a partir do poder local; e, por fim, refletir sobre o coronelismo político no Norte Central do Estado do Paraná, sobretudo nas pequenas cidades.

Os procedimentos metodológicos utilizados para a construção deste artigo foram: levantamento bibliográfico de assuntos pertinentes ao tema; levantamento de dados secundários dos municípios que compõem o Norte Central do Estado do Paraná: população total, população rural e número de eleitores; levantamento de dados eleitorais nos municípios que compõem o Norte Central do Estado do Paraná: número de eleições, número de prefeitos eleitos, número de prefeitos reeleitos, número de prefeitos com mais de uma eleição e prefeitos com maior número de mandato - para isso, consideraram-se os dados disponibilizados na base do Tribunal Superior Eleitoral (TSE) entre 1947 (primeira eleição disponibilizada) até 2016 (última eleição disponibilizada); produção de material cartográfico, como tabelas, gráficos e mapas; e, finalmente, realização da redação final deste artigo.

Quanto ao debate teórico sobre o método, este artigo ancora-se, teoricamente, entre outros autores, em Bauman (2007), Costa (1992), Castro (2013), Trigal e Del Pozo (1999), Leal (1975) e Sobarzo-Miño (2004). Já acerca da análise dos dados, o artigo contempla uma perspectiva quanti-qualitativa de análise, apresentando dados quantitativos que articulados e analisados à luz da base teórica demonstram cenários qualitativos acerca da realidade eleitoral da região Norte Central paranaense.

A região Norte Central paranaense, apresentada na Figura 1, é composta por 79 municípios, correspondendo, segundo o Instituto Brasileiro de Geografia e Estatística (IBGE, 2010), a uma área de pouco mais de 12 mil km² (12\% da área do Estado do Paraná) e a 2.037.151 habitantes (19\% da população do Paraná). A abordagem regional atende à preocupação deste artigo em não tratar os municípios isoladamente com fatos e 
ocorrências políticas como se se fossem exclusivas em cada um deles. Logo, a realidade apresentada neste artigo atinge com maior intensidade algumas localidades, mas, como tendência, observa-se que as localidades da região Norte do Estado do Paraná, de forma geral, são atingidas igualmente pelo mesmo processo de poder local centralizado e de coronelismo.

Figura 1 - Mesorregião Norte Central paranaense. Municípios e sedes

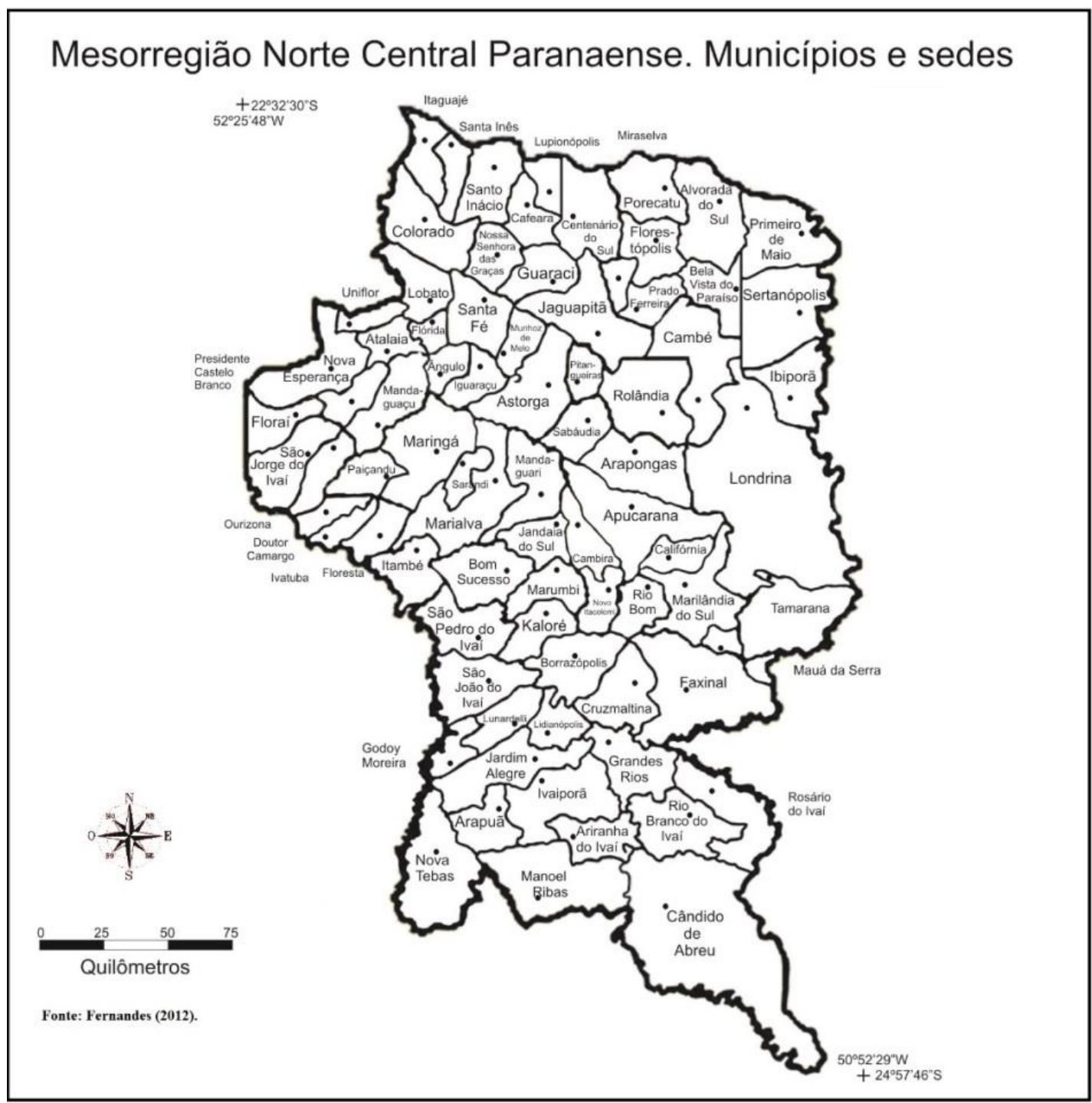

Fonte: Adaptado de Fernandes, P., 2012. 
O Norte do Estado do Paraná se configura como uma região marcada por densa rede urbana, sobretudo com pequenas cidades. Segundo Pedro Henrique Carnevalli Fernandes (2017, p. 141), a “maioria delas apresenta problemas relacionados a serviços de saúde, educação, infraestrutura, geração de emprego e renda, segurança, entre outros serviços importantes para o bem-estar coletivo". A região é bastante relevante para o estudo das dinâmicas urbanas e políticas, já que vivenciou, em pouco espaço de tempo, “transformações econômicas e socioespaciais que provocaram, inicialmente, uma imensa chegada de moradores (motivando inúmeras consolidações municipais) e, depois, uma imensa saída da população, diminuindo a densidade, a centralidade dos núcleos urbanos" (FERNANDES, P., 2017, p. 142).

Nesse sentido, o desenvolvimento do artigo ocorre a partir da seguinte estrutura, além da introdução (parte 1) e das considerações finais (parte 5): a segunda parte apresenta a base teórica da Geografia Política e da Geografia Eleitoral à luz da base teórica crítica; a terceira parte aborda a realidade política dos municípios do Norte Central do Estado do Paraná, enfatizando os resultados quantitativos das eleições de 1947 a 2016 (número de prefeitos diferentes, número de prefeitos reeleitos, número de prefeitos com mais de um mandato e proporção desses dados no número de eleições municipais no período referenciado); finalmente, a quarta parte transita por uma análise qualitativa dos resultados, debatendo a perspectiva do poder local e do coronelismo na região Norte Central do Estado do Paraná.

\section{Geografia política e geografia eleitoral}

O debate central acerca da Geografia Eleitoral precisa ser precedido de um aprofundamento teórico, ainda que sintético, da Geografia Política. A Geografia Eleitoral se insere, como um fragmento científico, na própria Geografia Política. Por isso, inicia-se a base teórica com uma breve explanação sobre a Geografia Política.

De acordo com Andrade (1989, p. 7), a "Geografia Política, [...] é um dos enfoques da ciência geográfica no qual se estuda a distribuição dos estados pela superfície da Terra, o problema do estabelecimento de fronteiras e os tipos de organização do 
território a que eles dão origem" (ANDRADE, 1989, p. 7). Dialogando com isso, Costa (1992, p. 18) identifica-a como "o conjunto de estudos sistemáticos mais afetos à geografia e restritos às relações entre o espaço e o Estado, questões relacionadas à posição, situação, características das fronteiras etc.”. Essas são características da fase clássica da Geografia Política.

Na década de 1970, a Geografia Política se renovou em torno do uso de modelos, técnicas estatísticas, principalmente a chamada "teoria dos sistemas" (COSTA, 1992). Assim, as novas modernizações exibiram uma abordagem contemplando as circunstâncias de produção e de circulação (COSTA, 1992), despertando novas inquietações em muitos geógrafos. O momento atual das pesquisas em Geografia Política associa-se às transformações teóricas e metodológicas dentro da Geografia Social, sobretudo quanto ao entendimento do Estado moderno pela nacionalidade, línguas, moedas etc.; pelas questões de fronteira; pelas múltiplas escalas de poder, inclusive a política; e, por fim, pela Geografia Eleitoral.

A Geografia Eleitoral busca "compreender, de um lado, como os interesses no território resultam em estratégias para a obtenção de respostas favoráveis do sistema representativo; por outro lado, identificar os modos pelos quais a organização do espaço pode afetar a decisão do eleitor" (CASTRO, 2013, p. 139-140). Assim, para Augusto (2012, p. 26), "a Geografia Eleitoral [...] foi refém do esquecimento dentro da Geografia Política, pois aborda, em seu cerne, relações de poder a partir das eleições e do Estado".

Então, sobre o surgimento dessa vertente da Geografia Política, é fundamental pontuar que os estudos em Geografia Eleitoral se iniciam em 1913, com os pioneiros André Siegfried, na França, e Carl Sauer, nos Estados Unidos, sendo que "o primeiro elaborou uma detalhada cartografia eleitoral aplicada ao seu país. Já o segundo, centrou seus estudos na delimitação de distritos eleitorais" (AUGUSTO, 2012, p. 28).

Terron (2012) avança acerca da metodologia dos fenômenos políticos: enquanto a metodologia francesa se consolidou como a associação de representações cartográficas descritivas e estatísticas para compreender os fenômenos políticos, nos países de língua 
inglesa (sobretudo Estados Unidos da América e Inglaterra), a Geografia Eleitoral se desenvolveu com uma linha mais fundamentada em métodos quantitativos espaciais.

No Brasil, segundo Augusto (2012), os estudos eleitorais são produzidos na quase totalidade pela Ciência Política e pela Sociologia, sendo que a Geografia Eleitoral é utilizada marginalmente por essas ciências. Logo, para superar isso, é preciso romper a dualidade "Geografia Eleitoral ou Geografia do Voto?" (CODATTO; SANTOS, 2006) e a construção de trabalhos que visam apenas mapear os dados e avançar sobre aspectos mais profundos e qualitativos. Acredita-se, portanto, que esse debate fundamental só será possível, segundo a perspectiva teórica e metodológica deste artigo, a partir da análise da Geografia Eleitoral associada à Geografia do Poder e às questões sociais.

A Geografia Eleitoral contribui para dar visibilidade aos marcos espaciais e às condições que afetam o voto e os resultados das eleições (CASTRO, 2013). Já segundo Trigal e Del Pozo (1999), a Geografia Eleitoral é fruto de análises das relações entre o espaço e os resultados das consultas populares (ou seja, o voto), fazendo parte da Geografia Política.

Los manuales y diccionarios geográficos al uso definem la Geografia como el análisis de la relaciones entre el espacio y los resultados de la consulta populares, y singularizan este tipo de estúdios como una rama específica de la Geografia, incluída en unos casos como parte del cuerpo disciplinar de la Geografia Política o simplemente como um elemento más de la Geografia Humana. (TRIGAL; DEL POZO, 1999, p. 196)

Augusto (2012) aponta que os estudos na área da Geografia Eleitoral pós-1970, quando se renovaram, aparecem centrados em dois temas básicos: "a análise dos sistemas eleitorais, em particular dos marcos espaciais que produzem as consultas eleitorais; e as análises dos resultados eleitorais em relação aos elementos espaciais que podem condicionar o voto" (AUGUSTO, 2012, p. 28). Já os estudos de casos em Geografia Eleitoral, considerados limitados por Castro (2013), exprimem a exploração sobre a intersecção entre o espaço e o momento crucial da democracia, voto e processo eleitoral, que, por sinal, "enseja, no momento de votar, um ritual que coloca em suspensão a vida 
política e instala a possibilidade de renovação do contrato da sociedade com os seus governantes. Parte desta magia pode ser explicada pela geografia" (CASTRO, 2013, p. 160).

Esse processo eleitoral evidenciado pelo autor se apropria da Geografia, sobretudo pelo espaço geográfico e pelo território, e também da Cartografia, que se torna um recurso fundamental para a evidenciação dos votos (CASTRO, 2013). Desse modo, pode-se observar que o foco atual da Geografia Eleitoral teve seus aspectos enriquecidos e transformados a partir da soma das contribuições de cada corrente teórica e epistemológica.

Atualmente, “a Geografia Eleitoral não está preocupada com o momento inicial dos processos eleitorais, mas com o eleitorado e as fases intermediárias" (AUGUSTO, 2012, p. 29). Essa abordagem faz com que a Geografia Eleitoral busque, em primeiro plano, os estudos que relacionam o poder e o espaço em distintas escalas e, na sequência, as consequências territoriais providas pelos processos eleitorais (TRIGAL; DEL POzO, 1999). Seguindo essa perspectiva, Castro (2013, p. 162) aponta que "a interpretação dos sistemas e dos processos eleitorais, além da distribuição territorial da decisão do eleitor, constitui um elemento a mais para explicar as diferentes tensões e conflitos que afetam as formas de organização do espaço". Sendo assim, a decisão do voto é considerada o ponto final de um processo de múltiplas influências que cada um dos eleitores recebe no seu contexto socioeconômico e cultural e, por conseguinte, isso torna a interpretação da capacidade de influência dos fatores pertencentes ao contexto importante elemento analítico da Geografia Eleitoral (AUGUSTO, 2012).

Portanto, especificamente associando à essência deste artigo, pode-se afirmar que a Geografia Eleitoral possibilita entender as construções das relações personalistas entre os candidatos e eleitores a partir, entre outros, das eleições municipais, resultando em inúmeras situações significativas no contexto político, como as relações de poder, de dependência e de personificação da política. Para entender mais esse cenário, parte-se para os resultados empíricos acerca da região Norte Central do Estado do Paraná. 


\section{As eleições municipais no norte central do Paraná entre 1947 e 2016}

O entendimento das relações de poder na política municipal passa, principalmente, pela eleição para o Poder Executivo Municipal, ou seja, para a função de prefeito. Nesse sentido, foi realizado um levantamento dos prefeitos eleitos nos 79 municípios da Mesorregião Norte Central paranaense, de 1947 a 2016. É fundamental ressaltar que as observações seguintes não visam avaliar as ações e a qualidade de cada governo municipal. Também não se pretende qualificar ou debater o direito à reeleição. $\mathrm{A}$ essência do debate está no poder local marcado pela presença do coronelismo no Norte Central do Paraná.

Na sequência, a próxima parte tem análises qualitativas, que associam os dados à base teórica à luz do debate da Geografia Eleitoral, pelo poder e pelo coronelismo, gerando reflexões e inquietações acerca da política e da personificação dos agentes políticos. Especificamente neste artigo, utilizou-se o termo coronelismo pelo entendimento da personificação da política em indivíduos ou famílias, o que, muitas vezes, impede o amadurecimento da cultura política de participação e representatividade popular, de controle e de transparência pública, pois a população local acaba por apoiar, muitas vezes de forma involuntária, a perpetuação no poder e fica à mercê de interesses particulares e/ou de grupos familiares.

Assim, considerando todas as eleições municipais realizadas nos 79 municípios, entre 1947 e 2016, a quantidade de pleitos somou 1.075 eleições. Efetivamente, a quantidade de eleições em cada município depende de dois principais fatores: (i) a data de consolidação municipal, ou seja, os municípios mais antigos possuem eleições de 1947, enquanto os municípios emancipados mais recentemente tiveram sua primeira eleição em 1996, quase cinquenta anos depois; (ii) os casos de afastamento do prefeito e a convocação, pelo órgão responsável, de novas eleições.

Nesse sentido, a Tabela 1 apresenta os municípios com maior quantidade de eleições e os municípios com menor quantidade de eleições, entre 1947 e 2016, no Norte Central do Estado do Paraná. 
Tabela 1 - Norte Central do Paraná. Quantidade de eleições municipais, 1947-2016

\begin{tabular}{|c|c|c|c|c|c|}
\hline Rank. & Município & Quantidade & Rank. & Município & Quantidade \\
\hline $\mathbf{0 1}$ & Rolândia & 19 & $\mathbf{7 0}$ & Lidianópolis & 7 \\
\hline $\mathbf{0 2}$ & Londrina & 18 & - & Mauá da Serra & 7 \\
\hline- & Mandaguari & 18 & - & Novo Itacolomi & 7 \\
\hline $\mathbf{0 4}$ & Apucarana & 17 & - & Pitangueiras & 7 \\
\hline- & Arapongas & 17 & $\mathbf{7 4}$ & Arapuã & 6 \\
\hline- & $\begin{array}{c}\text { Bela Vista do } \\
\text { Paraíso }\end{array}$ & 17 & - & Ariranha do Ivaí & 6 \\
\hline- & Cambé & 17 & - & Cruzmaltina & 6 \\
\hline- & Ibiporã & 17 & - & Prado Ferreira & 6 \\
\hline- & Porecatu & 17 & - & Rio Branco do & 6 \\
\hline- & Sertanópolis & 17 & - & Tamaí & 6 \\
\hline
\end{tabular}

Fonte: Adaptado de BRASIL, 2018. Elaboração: autores, 2018.

O município de Rolândia apresentou a maior quantidade: 19 eleições no período de 1947 a 2016. Isso porque enfrentou duas eleições suplementares, em 1970 e em 2015, ou seja, fora do calendário normal de eleições. Os municípios mais antigos, com eleições desde 1947, possuem 17 eleições municipais, todas em calendário normal de eleições, como Apucarana, Arapongas e Porecatu, por exemplo. Já Londrina e Mandaguari tiveram uma eleição suplementar, em 2009 e em 1953, respectivamente. No outro extremo da tabela aparecem os municípios que possuem as menores quantidades de eleições municipais entre 1947 e 2016. Os municípios de Arapuã, Ariranha do Ivaí, Cruzmaltina, Prado Ferreira, Rio Branco do Ivaí e Tamarama apresentaram seis eleições cada um. Todos eles são municípios que tiveram a primeira eleição em 1996 e, portanto, estão com calendário normal de eleições municipais.

A partir do número de eleições municipais realizadas, buscou-se entender a diferenciação de prefeitos municipais no período de 1947 a 2016. Então, considerando as 1.075 eleições realizadas, foram encontrados 762 prefeitos diferentes, gerando uma taxa de diferenciação de 70,9\%. Nesse ponto, é fundamental esclarecer que, para a “diferenciação de prefeito”, considerou-se a quantidade de pessoas diferentes que governaram prefeituras municipais no período de 1947 a 2016. 
Além disso, é importante pontuar que a lei que instituiu a reeleição no sistema eleitoral brasileiro foi a Emenda Constitucional $n^{\circ} 16$, de 4 de junho de 1997, que acrescentou o $\S 5^{\circ}$ ao art. 14 da Constituição da República (BRASIL, 1997). Ela foi promulgada durante o primeiro mandato presidencial de Fernando Henrique Cardoso (1995-1998), o que possibilitou, pela primeira vez, uma reeleição presidencial no Brasil: o segundo mandato de FHC (1999-2002). Os presidentes seguintes, Luiz Inácio Lula da Silva (2003-2010) e Dilma Rousseff (2011-2016), também foram reeleitos pelas urnas, tendo gozado dessa reeleição, diferentes de FHC, que no primeiro mandato presidencial aprovou no Congresso Nacional a reeleição e acabou "beneficiado" pela lei e sendo reeleito pelos votos. Entre todos os presidentes reeleitos no Brasil, por enquanto, apenas a presidente Dilma enfrentou o impedimento, quando do seu segundo mandato.

A Tabela 2 apresenta os municípios com as maiores proporções de prefeitos diferentes em relação à quantidade de eleições e os municípios com as menores proporções de prefeitos diferentes em relação à quantidade de eleições, entre 1947 e 2016, no Norte Central do Estado do Paraná.

Tabela 2 - Norte Central do Paraná. Proporção de prefeitos diferentes, 1947-2016

\begin{tabular}{|c|c|c|c|c|c|c|c|}
\hline Rank. & Município & Eleições & Proporção & Rank. & Município & Eleições & Proporção \\
\hline $\mathbf{0 1}$ & Rosário do Ivaí & 08 & $100,0 \%$ & $\mathbf{6 9}$ & Cambé & 17 & $58,8 \%$ \\
\hline $\mathbf{0 2}$ & Ivaiporã & 14 & $92,9 \%$ & $\mathbf{7 0}$ & Ivatuba & 14 & $57,1 \%$ \\
\hline $\mathbf{-}$ & Jardim Alegre & 14 & $92,9 \%$ & - & Marumbi & 14 & $57,1 \%$ \\
\hline $\mathbf{0 4}$ & Ibiporã & 17 & $88,2 \%$ & $\mathbf{7 2}$ & Mauá da Serra & 07 & $57,1 \%$ \\
\hline $\mathbf{0 5}$ & Ângulo & 08 & $87,5 \%$ & - & $\begin{array}{c}\text { Novo } \\
\text { Itacolomi }\end{array}$ & 07 & $57,1 \%$ \\
\hline $\mathbf{0 6}$ & Califórnia & 15 & $86,7 \%$ & - & Pitangueiras & 07 & $57,1 \%$ \\
\hline $\mathbf{0 7}$ & Flórida & 14 & $85,7 \%$ & $\mathbf{7 5}$ & Cafeara & 16 & $56,3 \%$ \\
\hline $\mathbf{0 8}$ & Grandes Rios & 12 & $83,3 \%$ & - & Cândido de & 16 & $56,3 \%$ \\
\hline $\mathbf{0 9}$ & Ariranha do Ivaí & 06 & $83,3 \%$ & $\mathbf{7 7}$ & $\begin{array}{c}\text { Pres. Castelo } \\
\text { Branco }\end{array}$ & 13 & $53,8 \%$ \\
\hline $\mathbf{1 0}$ & Maringá & 16 & $81,3 \%$ & $\mathbf{7 8}$ & Nova Tebas & 08 & $50,0 \%$ \\
\hline $\mathbf{-}$ & Primeiro de Maio & 16 & $81,3 \%$ & $\mathbf{7 9}$ & Prado Ferreira & 06 & $50,0 \%$ \\
\hline
\end{tabular}

Fonte: Adaptado de BRASIL, 2018. Elaboração: autores, 2018. 
Entre os 79 municípios da região, 42 (53,2\%) apresentaram taxas de diferenciação de prefeito maiores que a média regional de 70,9\%. Deles, 11 municípios (13,9\% do total) tiveram taxas maiores que $80,0 \%$ e outros 11 municípios ficaram com taxas menores que 60,0\%. O município de Rosário do Ivaí enfrentou oito eleições e elegeu oito prefeitos diferentes, gerando uma taxa de diferenciação de 100\%. Ivaiporã e Jardim Alegre apresentaram taxas superiores a 90,0\%, sendo que ambos passaram por 14 eleições municipais e elegeram 13 prefeitos diferentes.

Em contrapartida, Nova Tebas e Prado Ferreira tiveram as menores proporções de diferenciação de prefeitos: em Nova Tebas, foram apenas quatro prefeitos diferentes em oito eleições municipais; já em Prado Ferreira, foram três prefeitos diferentes em seis eleições municipais. Entre os municípios com menores proporções, destaque para Cafeara e Cândido de Abreu que só elegeram nove prefeitos diferentes em 16 eleições, ou seja, taxa de diferenciação de $56,3 \%$.

Esses dados de diferenciação motivaram a construção da taxa de repetição de prefeitos, no período de 1947 a 2016, nos municípios do Norte Central do Estado do Paraná. Então, considerando os 762 prefeitos diferentes eleitos nas 1.075 eleições municipais, foram encontrados 251 prefeitos que repetiram o mandato, gerando uma taxa de repetição de $33 \%$. Para a repetição de prefeitos, consideraram-se os prefeitos que foram eleitos mais de uma vez para governar uma mesma prefeitura municipal no período de 1947 a 2016.

Assim, a Tabela 3 apresenta os municípios com as maiores proporções de prefeitos repetidos em relação à quantidade de prefeitos diferentes e os municípios com as menores proporções de prefeitos repetidos em relação à quantidade de prefeitos diferentes, entre 1947 e 2016, no Norte Central do Estado do Paraná.

Entre os 79 municípios da região, 47 (59,5\%) apresentaram taxa de repetição maior que a média regional. Entre eles, 19 (24\% do total) tiveram taxa de repetição igual ou maior que 50\% e outros 19 municípios ficaram com taxa de repetição menor que $25 \%$. Prado Ferreira apresentou 100,0\% de prefeitos repetidos, ou seja, os três diferentes prefeitos eleitos conseguiram uma nova eleição. Em Nova Tebas, dos quatro prefeitos 
eleitos, três conseguiram um novo mandato. Em Sabáudia, seis dos nove prefeitos eleitos conseguiram um novo mandato, gerando taxa de $66,7 \%$.

Em contrapartida, Rosário do Ivaí não apresentou taxa de repetição. Outros três municípios tiveram taxas de repetição de prefeitos menores que 10,0\%: Ivaiporã, Jardim Alegre e Ibiporã - neste último, dos 15 prefeitos eleitos, apenas um conseguiu uma nova eleição.

Tabela 3 - Norte Central do Paraná. Proporção de prefeitos repetidos, 1947-2016

\begin{tabular}{|c|c|c|c|c|c|c|c|}
\hline Rank. & Município & $\begin{array}{l}\text { Prefeitos } \\
\text { diferentes }\end{array}$ & Proporção & Rank. & Município & $\begin{array}{l}\text { Prefeitos } \\
\text { diferentes }\end{array}$ & Proporção \\
\hline 01 & $\begin{array}{l}\text { Prado } \\
\text { Ferreira }\end{array}$ & 03 & $100,0 \%$ & 61 & Apucarana & 13 & $23,1 \%$ \\
\hline 02 & Nova Tebas & 04 & $75,0 \%$ & - & $\begin{array}{l}\text { Bela Vista } \\
\text { do Paraíso }\end{array}$ & 13 & $23,1 \%$ \\
\hline 03 & $\begin{array}{c}\text { Pres. } \\
\text { Castelo } \\
\text { Branco }\end{array}$ & 07 & $71,4 \%$ & - & Londrina & 13 & $23,1 \%$ \\
\hline 04 & Sabáudia & 09 & $66,7 \%$ & - & Maringá & 13 & $23,1 \%$ \\
\hline 05 & $\begin{array}{c}\text { Borrazópoli } \\
\text { s }\end{array}$ & 09 & $55,6 \%$ & 65 & $\begin{array}{l}\text { Doutor } \\
\text { Camargo }\end{array}$ & 10 & $20,0 \%$ \\
\hline- & $\begin{array}{c}\text { Cândido de } \\
\text { Abreu }\end{array}$ & 09 & $55,6 \%$ & - & $\begin{array}{l}\text { Grandes } \\
\text { Rios }\end{array}$ & 10 & $20,0 \%$ \\
\hline- & Lobato & 09 & $55,6 \%$ & - & $\begin{array}{l}\text { Lupionópo } \\
\text { lis }\end{array}$ & 10 & $20,0 \%$ \\
\hline- & $\begin{array}{c}\text { Manoel } \\
\text { Ribas }\end{array}$ & 09 & $55,6 \%$ & - & Ourizona & 10 & $20,0 \%$ \\
\hline 09 & Rolândia & 12 & $50,0 \%$ & 69 & $\begin{array}{l}\text { Ariranha } \\
\text { do Ivaí }\end{array}$ & 05 & $20,0 \%$ \\
\hline 10 & Cambira & 10 & $50,0 \%$ & 70 & Itaguajé & 11 & $18,2 \%$ \\
\hline 11 & Marumbi & 08 & $50,0 \%$ & 71 & Flórida & 12 & $16,7 \%$ \\
\hline- & $\begin{array}{l}\text { São João } \\
\text { do Ivaí }\end{array}$ & 08 & $50,0 \%$ & - & Iguaraçu & 12 & $16,7 \%$ \\
\hline 13 & Lunardelli & 06 & $50,0 \%$ & 73 & Califórnia & 13 & $15,4 \%$ \\
\hline- & Sarandi & 06 & $50,0 \%$ & - & $\begin{array}{l}\text { Primeiro } \\
\text { de Maio }\end{array}$ & 13 & $15,4 \%$ \\
\hline 15 & $\begin{array}{c}\text { Cruzmaltin } \\
\mathrm{a}\end{array}$ & 04 & $50,0 \%$ & 75 & Ângulo & 07 & $14,3 \%$ \\
\hline- & $\begin{array}{c}\text { Mauá da } \\
\text { Serra }\end{array}$ & 04 & $50,0 \%$ & 76 & Ivaiporã & 13 & $7,7 \%$ \\
\hline
\end{tabular}




\begin{tabular}{|c|c|c|c|c|c|c|c|}
\hline- & $\begin{array}{c}\text { Novo } \\
\text { Itacolomi }\end{array}$ & 04 & $50,0 \%$ & - & $\begin{array}{c}\text { Jardim } \\
\text { Alegre }\end{array}$ & 13 & $7,7 \%$ \\
\hline- & $\begin{array}{c}\text { Pitangueira } \\
\text { s }\end{array}$ & 04 & $50,0 \%$ & 78 & Ibiporã & 15 & $6,7 \%$ \\
\hline- & $\begin{array}{c}\text { Rio Branco } \\
\text { do Ivaí }\end{array}$ & 04 & $50,0 \%$ & 79 & $\begin{array}{c}\text { Rosário do } \\
\text { Ivaí }\end{array}$ & 08 & $0,0 \%$ \\
\hline
\end{tabular}

Fonte: Adaptado de BRASIL, 2018. Elaboração: autores, 2018.

É interessante destacar as duas maiores cidades do interior do Estado do Paraná: Londrina e Maringá, respectivamente. Ambas apresentaram 13 prefeitos diferentes eleitos entre 1947 e 2016, sendo que apenas três deles conseguiram um novo mandato, o que gera uma hipótese para novos estudos: a confluência do adensamento populacional e da urbanização - somado ao crescimento dos setores secundário e terciário da economia e possível maior tempo de frequência escolar pela população - podem ser fatores dissipadores da influência de "coronéis" na política formal e no eleitorado (a influência das famílias de “coronéis" permanece marcante nos municípios demograficamente menores da região).

Finalmente, é relevante abordar os dados de reeleição. Como destacado, a reeleição presidencial no Brasil passou a ser possível a partir de 1997, sendo o primeiro presidente reeleito já no ano seguinte, em 1998, e tal regra sendo válida para as eleições municipais, a partir de 2000. Nas eleições de 1996, todos os 79 municípios da região já eram consolidados politicamente e, portanto, passaram por processos eleitorais. Considerando os 762 prefeitos diferentes eleitos na região, nas 1.075 eleições municipais, foram encontrados 131 prefeitos que conseguiram, ao menos, uma reeleição, ou seja, oito anos seguidos de mandato, gerando uma taxa de reeleição de $17,2 \%$.

Assim, a Tabela 4 apresenta os municípios com a maior quantidade de prefeitos reeleitos e a maior taxa de reeleição em relação à quantidade de eleições e os municípios sem prefeitos reeleitos e, portanto, sem taxa de reeleição em relação à quantidade de eleições, no período de 2000 a 2016, no Norte Central do Estado do Paraná. 
Tabela 4 - Norte Central do Paraná. Quantidade de prefeitos reeleitos e taxa de reeleição, 2000-2016

\begin{tabular}{|c|c|c|c|c|c|c|c|}
\hline Rank. & Município & \begin{tabular}{|l|} 
Prefeitos \\
reeleitos
\end{tabular} & Proporção & Rank. & Município & \begin{tabular}{l|} 
Prefeitos \\
reeleitos
\end{tabular} & Proporção \\
\hline 01 & Cafeara & 03 & $100,0 \%$ & & & & \\
\hline- & $\begin{array}{l}\text { Centenário do } \\
\text { Sul }\end{array}$ & 03 & $100,0 \%$ & & & & \\
\hline- & Floraí & 03 & $100,0 \%$ & & & & \\
\hline \multirow[t]{2}{*}{-} & Jaguapitã & 03 & $100,0 \%$ & & & & \\
\hline & Manoel Ribas & 03 & $100,0 \%$ & & & & \\
\hline- & $\begin{array}{c}\text { Munhoz de } \\
\text { Melo }\end{array}$ & 03 & $100,0 \%$ & & & & \\
\hline- & Prado Ferreira & 03 & $100,0 \%$ & & & & \\
\hline- & $\begin{array}{c}\text { Presidente } \\
\text { Castelo Branco }\end{array}$ & 03 & $100,0 \%$ & 75 & $\begin{array}{c}\text { Ariranha do } \\
\text { Ivaí }\end{array}$ & 00 & $0,0 \%$ \\
\hline- & Rolândia & 03 & $100,0 \%$ & - & $\begin{array}{c}\text { Bom } \\
\text { Sucesso }\end{array}$ & 00 & $0,0 \%$ \\
\hline- & Sabáudia & 03 & $100,0 \%$ & - & Ivaiporã & 00 & $0,0 \%$ \\
\hline- & $\begin{array}{c}\text { São João do } \\
\text { Ivaí }\end{array}$ & 03 & $100,0 \%$ & - & $\begin{array}{c}\text { Jandaia do } \\
\text { Sul }\end{array}$ & 00 & $0,0 \%$ \\
\hline- & $\begin{array}{l}\text { São Jorge do } \\
\text { Ivaí }\end{array}$ & 03 & $100,0 \%$ & - & $\begin{array}{l}\text { Rosário do } \\
\text { Ivaí }\end{array}$ & 00 & $0,0 \%$ \\
\hline
\end{tabular}

Fonte: Adaptado de BRASIL, 2018. Elaboração: autores, 2018.

Entre os 79 municípios do Norte Central do Paraná, 12 (15,2\%) apresentaram três prefeitos reeleitos, ou seja, 100,0\% das possibilidades de reeleição no período. Em 33 municípios (41,8\%), ocorreram dois prefeitos reeleitos, ou seja, $66,7 \%$ de taxa de reeleição. Em 29 municípios (36,7\%), apenas um prefeito foi reeleito, ou seja, 33,3\% de taxa de reeleição. Finalmente, em cinco municípios (6,3\% do total), nenhum prefeito conseguiu a reeleição no período. Na próxima parte, os dados são analisados à luz da Geografia Eleitoral, pelo poder e coronelismo, gerando reflexões qualitativas acerca do poder local na região do Norte Central paranaense. 


\section{Poder local e coronelismo no Norte Central do estado do Paraná}

O debate proposto nesta parte do artigo caminha no sentido de entender o papel do poder local pelo coronelismo no espaço geográfico do Norte Central paranaense, sendo que "o espaço envolve o poder e o poder significa controle e dominação" (SOBARZO MIÑO, 2004, p. 53). Nesse sentido, segundo Sobarzo Miño (2004, p. 57), "a ideia do poder municipal como zelador dos interesses coletivos deve ser assumida como um ideal não cumprido ou, pelo menos, não cumprido totalmente", já que, em muitos casos, as ações realizadas pelo poder municipal ocorrem por meio de uma mistura de interesses públicos e privados, inclusive de interesses próprios do prefeito ou de seu grupo familiar.

As pequenas cidades apresentam uma especificidade quanto ao poder local. É comum nessas localidades o poder local ser vinculado a dois grupos políticos, em uma dicotomia de "situação" versus "oposição", mesmo que as nomenclaturas não sejam efetivamente opostas às políticas implementadas e utilizadas pelo governo que estiver na considerada “situação". Sendo assim, o comando da política, em muitas pequenas cidades - e não exclusivamente nelas -, independente da questão partidária, acaba não dispensando "a referência ao coronelismo" (ENDLICH, 2006, p. 306). Tal situação não é excludente em cidades médias e/ou metrópoles, no entanto, reforça a hipótese levantada anteriormente acerca de fatores dissipadores das forças familiares e dos "coronéis".

De acordo com Leal (1975), a utilização do termo coronelismo no Brasil teve origem do seu sentido translato aos autênticos ou falsos coronéis da extinta Guarda Nacional, oriunda de 1831. Era comum, em cada município brasileiro, a existência de um regimento da Guarda Nacional, sendo que o posto de "coronel" era cedido ao chefe político da comuna (LEAL, 1975). Assim, em cada município, o comando da Guarda Nacional pertencia ao mais rico fazendeiro, ou ao comerciante, ou, ainda, ao industrial (LEAL, 1975). Os sertanejos chamavam esses comandantes de coronéis, sendo que essa mentalidade perdura até os dias de hoje.

A partir daquele contexto, Leal (1975) definiu o coronelismo como uma troca de conveniências entre o poder público e a influência social dos chefes locais, notadamente 
chamados de senhores de terra. Logo, o coronelismo fazia alusão à estrutura agrária brasileira. Com o passar do tempo e das transformações na estrutura urbana brasileira, alguns chefes municipais - "coronéis locais" -, depois de terem herdado ou consolidado a liderança local ou regional, se tornaram absenteístas (LEAL, 1975). Assim, chegam a ocupar cargos maiores, como deputados estaduais, deputados federais, senadores, governadores de Estado, cargos de secretaria, ministério, entre outros (LEAL, 1975).

Atualmente, em grande parte do Brasil urbano, os "coronéis" desapareceram, ou deixaram de ser os grandes donos de terras. Agora, eles existem como médicos, engenheiros, arquitetos e, principalmente, empresários, inclusive os proprietários dos meios de comunicação ("coronéis" proprietários de rádios, por exemplo). Evidentemente, no Brasil mais rural, ainda existem os donos de terras que são prefeitos municipais e/ou políticos influentes. Apesar da mudança nos tempos, os modelos de gestão são os mesmos, ou seja, mandatários, incontestáveis e paternalistas (LEAL, 1975).

A preservação do mandonismo relaciona-se com uma estrutura econômica e social inadequada. Diferentemente do que pode parecer, não demonstra força política local. Ao contrário, mediante a submissão do poder local a um forte centralismo, estabelece-se um compromisso e trocas de favores entre os donos do poder local e os comandantes das instâncias superiores. (ENDLICH, 2006, p. 307)

Partindo disso, Endlich (2006) lembra que, devido ao compromisso, as autoridades estaduais e federais fecham os olhos a quase todos os atos do poder local, inclusive aqueles relacionados à violência, repressão, coação, represália, entre outras atitudes. São exemplos os casos de compra e venda de voto, de fraude eleitoral e manipulação de votos que permeiam a sociedade brasileira.

No Norte Central do Estado do Paraná, inúmeros casos materializam a base teórica do poder local pelo coronelismo. Na sequência, algumas reflexões sobre o papel político personificado ou em grupos dominantes em municípios do Norte Central paranaense. Todavia, antes, é fundamental, mais uma vez, explicar o sentido apropriado do 
coronelismo neste artigo: a manutenção de pessoas e/ou grupos familiares no cargo do Poder Executivo local, personificando a política local.

A maior quantidade de mandatos em um mesmo município da região foi de quatro mandatos, ou seja, 16 anos de governo do mesmo prefeito. Isso ocorreu em cinco municípios da região: Cambé, Ivatuba, Londrina, Lupionópolis e Ourizona. Em Ivatuva, município de 51 anos, um prefeito governou o município por 16 anos e outro prefeito por 12 anos, ou seja, ambos estiveram no poder em mais da metade da idade do município. Em Lupionópolis, município de 60 anos, dois prefeitos conseguiram quatro mandatos: o primeiro acumulou 16 anos de cargo como prefeito (31\% do tempo do município emancipado), enquanto o segundo somou 18 anos (30\% da idade municipal) - apenas esses dois somam $61 \%$ do tempo de emancipação do município.

Em 42 municípios da região (53\%), ao menos um prefeito conseguiu três mandatos no Poder Executivo, sendo que em Cafeara, município de 62 anos de idade, três prefeitos “conseguiram" intercalar três mandatos cada um, totalizando 36 anos de governo (50\% da idade do município) e em (ândido de Abreu, Marumbi, Porecatu e Rio Bom, dois prefeitos tiveram três mandatos cada um, totalizando 24 anos de governo. Em Sabáudia, seis prefeitos diferentes conseguiram repetir um mandato e em Cambira, Mandaguari e Marialva cinco prefeitos tiveram dois mandatos.

Em Floresta, houve o maior intervalo de tempo entre o primeiro e o segundo mandato de um mesmo prefeito: 32 anos, ou seja, foi eleito pela primeira vez em 1976 e, pela segunda, em 2008. Em Ivatuba e em Manoel Ribas, o prefeito foi eleito em 1982 e, depois, em 2004, ou seja, 22 anos depois. Em Bom Sucesso, município de 57 anos, durante 29 anos $(50,1 \%)$ duas famílias se revezaram no poder. Já em Porecatu, duas famílias venceram oito das 15 eleições municipais (53\%). Existem, também, vários casos de parentescos na função de prefeito, como em Cambira e Nova Esperança, onde cônjuges somam quatro mandatos (16 anos de governo), e em Santa Fé, onde pai e filho somam cinco mandatos (20 anos de governo).

Em Arapuã (21 anos de idade) e Tamarana (23 anos de idade), aconteceram apenas seis administrações municipais, das quais quatro foram da mesma família. Nos municípios 
de Ivatuba, Nossa Senhora das Graças, Ourizona e Sertanópolis, considerando quatro eleições consecutivas, três foram vencidas pelo mesmo prefeito. Finalmente, existe um caso em que o mesmo prefeito foi eleito em dois municípios vizinhos, Santo Inácio, em 1952, e Santa Inês, em 1961, separados por 18 quilômetros.

Em Kaloré, município de 4.506 habitantes (IBGE, 2010), uma situação dramática para os moradores reflete o cenário político oligárquico regional. A crise política no município começou após a eleição de 2004, quando um prefeito chegou ao seu terceiro mandato. O candidato derrotado naquela eleição denunciou o vencedor, que acabou sendo cassado, junto com seu vice, por abuso de poder. Assim, o denunciante assumiu a prefeitura e foi reeleito em 2008. Então, o candidato derrotado em 2008 formalizou uma denúncia contra o vencedor, que acabou sendo cassado também por abuso do poder, como o prefeito anterior que ele havia denunciado. Após o episódio, começou uma concessão de liminares que acarretou quatro prefeitos diferentes no município. Em 2011, o Tribunal Regional Eleitoral do Paraná convocou eleição suplementar para 27 de março, porém ela foi cancelada e adiada para $1^{\circ}$ de maio. Próximo da data, o pleito foi novamente cancelado e reagendado para 3 de julho, quando efetivamente ocorreu. O prefeito eleito em 2011 não se reelegeu em 2012 e o vencedor de 2012 conseguiu a reeleição em 2016.

Quando se trata de política, sobretudo em pequenas cidades, são inúmeros casos de repressão, ameaça e troca de favores. No período eleitoral, várias pequenas cidades entram em verdadeiro "clima de guerra". As pessoas são reconhecidas pelo "lado" em que se posicionam na disputa. Sobre isso, Caniello (2003) destaca o cenário das eleições municipais na pequena cidade de São João Nepomuceno (MG): são dois grupos políticos que disputam o poder e a máquina pública em eleições marcadas por violências, verbais e físicas. O ápice ocorreu em 1926, por "uma polêmica banal, a troca do nome da praça principal", quando a transformaram em um campo de batalha, com quatro mortes (CANIELLO, 2003, p. 42).

Especificamente no Norte Central do Paraná, os exemplos se multiplicam e aparecem em diversas cidades, como os quatro casos apresentados na sequência. Em Alvorada do Sul, de 10.283 habitantes (IBGE, 2010), "a união temporária para organização das festas cede lugar à ruptura temporária ocasionada no 'tempo da política' (...) 
marcado pelas brigas assumidas e aceitas como legítimas pelos sitiantes" (MUNHOS, 2007, p. 83).

Em Ariranha do Ivaí, pequena cidade de 2.453 habitantes (IBGE, 2010), um vereador, presidente da Câmara, foi alvo, em 2012, de um atentado em sua residência, quando durante a madrugada quatro tiros atingiram a janela, o guarda-roupa e a parede do quarto (CASA..., 2012). Em Jardim Alegre, município de 12.324 habitantes (IBGE, 2010), em 2001, um vereador foi morto com dez tiros por crime político (VEREADOR..., 2001).

Em Manoel Ribas, de 13.169 moradores (IBGE, 2010), as eleições de 2004 ficaram marcadas por vários casos de violência pela dualidade que Fernandes (2006) chamou de “disputa do 15 com o 23", em referência aos números dos partidos. Logo, "a escola, a enfermaria e mesmo a distribuição do leite (promovida pela prefeitura) foram afetadas pela violência do faccionalismo político atualizado com a disputa entre os grupos do '15' e do '23"' (FERNANDES, R., 2006, p. 32). Entretanto, o coronelismo não ocorre apenas nas pequenas cidades. De acordo com Sobarzo Miño (2004, p. 65), “o público parece se concentrar e, finalmente, personificar-se na figura do prefeito [...] remetendo-nos às práticas dos coronéis nos primeiros tempos da criação da cidade".

No caso do Norte Central paranaense, Londrina e Maringá também possuem redutos políticos personificados em indivíduos e/ou famílias. No município de Arapongas, quarto maior em população da região, com 104.105 habitantes (IBGE, 2010), uma família elegeu prefeitos por cinco oportunidades, outra família teve quatro mandatos e uma terceira família, dois mandatos, concentrando 73\% das eleições municipais. Ou seja, nos últimos 40 anos três famílias revezaram no poder municipal de Arapongas.

Em Maringá, segundo maior em população da região e do estado, com 357.077 habitantes (IBGE, 2010) pai e dois filhos centralizam o poder local, com eleições desde 1972 - no total foram 16 anos em 48 (um terço do período). Em Londrina, maior cidade dessa região e do interior do Paraná, com 506.701 habitantes (IBGE, 2010), dois personagens da mesma família conseguiram cinco mandatos desde 1976, ou seja, vinte anos de governo dos 44 anos do período $-45 \%$. 
Assim, as ações municipais ficam limitadas ao interesse apenas dos detentores do poder. A prática oligárquica influencia na gestão das prefeituras dessa região do Paraná e de políticas públicas, tais como: obras e interesses privados em detrimento dos interesses públicos, abandono das áreas de lazer, (re)urbanização de áreas verdes apenas para interesse de proprietários do solo, comercialização dos lotes urbanos e valorização da áreas quase sempre de propriedades de determinados grupos, espaços privados constituídos com verbas públicas, infraestrutura adequada apenas em bairros que reforcem o poder dos “coronéis”, entre outras ações.

\section{Considerações finais}

A Geografia Política precisa avançar acerca dos debates, sobretudo nesse atual período de desconfiança política e afastamento social da vida pública e do espaço público. Além disso, o debate sobre esse tema coopera no aprofundamento das políticas públicas, especialmente para os menos favorecidos, pelo engajamento voltado à coletividade e à comunidade, fazendo com que o Estado amadureça em seu papel de ser um Estado social e político, em uma região com tradição e raiz oligárquica. Então, o papel do poder local e a defesa do espaço e da vida pública, sobretudo para uma sociabilidade positiva, precisa se reorganizar de modo a eliminar a política sustentada pelos "coronéis" e pelos interesses de suas famílias.

Por isso, este artigo buscou refletir acerca da Geografia Eleitoral no Norte Central do Estado do Paraná a partir do poder local (assentado no coronelismo), sobretudo em municípios polarizados por pequenas cidades. Para isso, as análises contemplaram as eleições municipais para o Poder Executivo, entre 1947 e 2016, sendo que os resultados tentaram descontruir o senso comum de que o coronelismo e a centralização política personificada em indivíduos ou famílias são características de áreas e regiões também menos desenvolvidas. Associado à base teórica, o artigo buscou demonstrar a realidade política da região Norte Central do Estado do Paraná e refletir sobre o coronelismo e o poder local. 
O debate teórico acerca da Geografia Política e da Geografia Eleitoral precisa ser aprofundado. Percebe-se, ainda, uma série de lacunas teóricas que serão preenchidas com uma ampliação dos estudos. A partir da década de 1970, a Geografia Política se renovou e se modernizou, sendo que, atualmente, ela se associa às transformações teóricas e metodológicas dentro da Geografia Social.

Entre essas possibilidades, surgiu o estudo da Geografia Eleitoral, que busca, em essência, compreender as estratégias do sistema representativo e identificar a organização do espaço e sua influência na decisão do eleitor (CASTRO, 2013). Em suma, é preciso transcender o "mapeamento" e a "distribuição" dos votos; é fundamental discutir aspectos mais profundos e qualitativos, sobretudo quanto ao poder e perpetuação de "coronéis" e das famílias que se repetem no poder.

$\mathrm{Na}$ Geografia Eleitoral, os estudos exprimem a exploração sobre a intersecção entre o espaço e o momento crucial da democracia, que é o voto e o processo eleitoral. Esse processo eleitoral é apropriado pela Geografia a partir do território, do espaço e do sujeito com a finalidade de compreender as consequências territoriais, espaciais e sociais. Portanto, a Geografia Eleitoral possibilita entender as construções das relações construídas, como as de poder, de dependência e de personificação da política.

A partir da associação da parte teórica com a parte empírica, o artigo tentou debater o papel do poder local no espaço geográfico do Norte Central paranaense, sobretudo pela ideia de Sobarzo Miño (2004) acerca do espaço envolvendo o poder e o poder significando o controle e dominação. As pequenas cidades apresentam especificidades quanto ao poder local, seja pela dicotomia política ("situação" versus “oposição”), seja pela personificação dos sujeitos e de grupos familiares. Assim, alicerçado na definição de coronelismo de Leal (1975), o artigo tentou demonstrar que há influência social dos chefes locais, sejam senhores de terra, empresários urbanos, médicos, engenheiros, arquitetos, entre outros, ou donos das riquezas, na maioria dos municípios do Norte Central paranaense. Portanto, influenciadas por isso, possivelmente, muitas ações municipais acabam limitadas aos interesses dos detentores do poder em detrimento dos interesses coletivos. 


\section{Referências}

ANDRADE, Manuel Correia de. Geopolítica do Brasil. São Paulo: Ática, 1989.

AUGUSTO, Daniel Cirilo. Geografia eleitoral e decisão do voto: uma análise a partir do eleitorado de Guarapuava-PR. 2012. Dissertação (Mestrado em Geografia) - Universidade Estadual do Centro Oeste, Guarapuava, 2012.

BAUMAN, Zygmunt. Tempos líquidos. Tradução de Carlos Alberto Medeiros. Rio de Janeiro: Zahar, 2007. 119 p.

BILENKY, Thais. Forças Armadas lideram confiança da população; Congresso tem descrédito. Folha de S. Paulo, São Paulo, 24 jun. 2017. Poder. Disponível em: http://www1.folha.uol.com.br/poder/2017/06/1895770-forcas-armadas-lideram-confiancada-populacao-congresso-tem-descredito.shtml. Acesso em: 15 ago. 2018.

BRASIL. Casa Civil. Subchefia para assuntos jurídicos. Emenda Constitucional $\mathbf{n}^{\circ} \mathbf{1 6}$, de 4 de junho de 1997. Disponível em: http://www.planalto.gov.br/ccivil_03/constituicao/ emendas/emc/emc16.htm. Acesso em: 22 dez. 2018.

BRASIL. Tribunal Superior Eleitoral. Eleitor e eleições: eleições. [Brasília: TSE], 2018. Disponível em: http://www.tse.jus.br/eleitor-e-eleicoes/eleicoes/eleicoes. Acesso em: 7 jan. 2019.

CANIELLO, Márcio. O Ethos Sanjoanense: tradição e mudança em uma cidade pequena. Mana, Rio de Janeiro, v. 9, n. 1, p. 31-56, 2003.

CASTRO, Iná. Elias. Geografia e política. 5. ed. Rio de Janeiro: Bertrand Brasil, 2013.

CHADE, Jamil. Brasileiro é quem menos confia em político, diz pesquisa mundial. O Estado de São Paulo, São Paulo, 11 maio 2016. Política. Disponível em:

http://politica.estadao.com.br/noticias/geral,brasileiro-e-quem-menos-confia-em-politico-diz-pesquisa-mundial,10000050380. Acesso em: 15 ago. 2018.

CODATTO, Adriano Nervo; SANTOS, José dos Santos. Partidos e eleições no Paraná: uma abordagem histórica. Curitiba: Edição do TRE-PR, 2006.

COSTA, Wanderley Messias da. Geografia política e geopolítica: discursos sobre o território e o poder. 2. ed. São Paulo: Edusp, 1992. 
ENDLICH, Angela Maria. Pensando os papéis e significados das pequenas cidades do Noroeste do Paraná. 2006. Tese (Doutorado em Geografia) - Universidade Estadual Paulista, Faculdade de Ciências e Tecnologia, Presidente Prudente, 2006.

FARIA, Flávia. Moro lidera ranking de confiança com um terço de notas 9 ou 10, diz Datafolha. Folha de S. Paulo, São Paulo, ano 99, n. 33149, 05 jan. 2020. Disponível em: https://www1.folha.uol.com.br/poder/2020/01/moro-lidera-ranking-de-confianca-com-umterco-de-notas-9-ou-10-diz-datafolha.shtml. Acesso em: 24 mai. 2020.

FERNANDES, Pedro Henrique Carnevalli. Sociabilidade e sentimento de insegurança urbana em pequenas cidades: o Norte do Paraná. 2012. Dissertação (Mestrado em Geografia) - Universidade Estadual de Maringá, Maringá, 2012.

FERNANDES, Pedro Henrique Carnevalli. Um espectro ronda as pequenas cidades: 0 aumento da violência e da insegurança objetiva. 2017. 525 p. Tese (Doutorado em Geografia) - Universidade Estadual de Maringá, Maringá, 2017.

FERNANDES, Ricardo Cid. O “15” e o "23": políticos e políticas kaingang. Campos, Curitiba, v. 7, n. 2, p. 27-47, 2006.

VEREADOR é morto com dez tiros no Paraná. Folha de S. Paulo, São Paulo, og jul. 2001. Disponível em: https://www1.folha.uol.com.br/folha/cotidiano/ult95u32621.shtml. Acesso em: 10 jun. 2020.

IBGE. Instituto Brasileiro de Geografia e Estatística. Censo Demográfico 2010. [Rio de Janeiro: IBGE], 2010. Disponível em: http://www.censo2010.ibge.gov.br. Acesso em: 22 ago. 2018.

IBOPE. Pesquisas: $38 \%$ consideram administração de Bolsonaro ruim ou péssima. [Rio de Janeiro: IBOPE], 2019. Disponível em: https://www.ibopeinteligencia.com/noticias-epesquisas/38-consideram-administracao-de-bolsonaro-ruim-ou-pessima. Acesso em: 24 maio 2020.

CASA de vereador é alvo de tiros. Jornal Repórter Do Vale. 2012. Disponível em: https://www.jornalreporterdovale.com/2012/02/. Acesso em: 10 de jun. 2020.

LEAL, Vitor Nunes. Coronelismo, enxada e voto: o município e o regime representativo, no Brasil. 2. ed. São Paulo: Alfa-Omega, 1975.

MUNHOS, Paula Daniela. Sitiantes e chacareiros do Ribeirão Vermelho, Alvorada do Sul PR: sociabilidade, disputas e transformações de um bairro rural. 2007. Dissertação (Mestrado em Ciências Sociais em Desenvolvimento, Agricultura e Sociedade). Universidade Federal Rural do Rio de Janeiro, Rio de Janeiro, 2007. 
OS PIORES (e os mais curiosos) projetos de lei dos nossos deputados. Revista Super Interessante, São Paulo, 31 out. 2016. Disponível em: https://super.abril.com.br/ideias/ospiores-e-os-mais-curiosos-projetos-de-lei-dos-nossos-deputados/. Acesso em: 15 ago. 2018.

SOBARZO MIÑO, Oscar Alfredo. Os espaços de sociabilidade segmentada: a produção do espaço público em Presidente Prudente. 2004. 221 p. Tese (Doutorado em Geografia) Universidade Estadual Paulista, Presidente Prudente, 2004.

TERRON, Sônia. Geografia eleitoral em foco. Revista Em Debate, Belo Horizonte, v. 4, n. 2, p. 8-18, maio 2012.

TRIGA, Lorenzo López; DEL POZO, Paz Benito. Geografia Política. In: TRIGA, Lorenzo López; DEL POZO, Paz Benito. El comportamiento electoral y los sistemas políticos. Madrid: Cátedra, 1999. 